\title{
Effects of Meso-scale Modeling on Concrete Fracture Parameters Calculation
}

\author{
Ali Permanoon ${ }^{1}$, Amir Houshang Akhaveissy ${ }^{1 *}$ \\ 1 Department of Civil Engineering, Faculty Engineering, \\ Razi University, P.O. Box: 67189-58894, Kermanshah, Iran \\ *Corresponding author, e-mail: akhaveissy@razi.ac.ir
}

Received: 12 February 2019, Accepted: 11 June 2019, Published online: 05 July 2019

\begin{abstract}
Mechanical fracture brings about considerable financial and living costs to various communities. Since the early twentieth century, the issue has been scientifically under scrutiny. Hence, it is of necessity to explore the failure of various materials including concrete as one of the most widely used materials in the construction industry. In examining the concrete structures, while it is assumed that concrete is a homogeneous material, it consists of several components such as cement paste, an aggregate of sand, gravel, and air, and the components play an essential role in determining correct concrete behavior. Hence, in the present research, to calculate the concrete fracture parameters under the three-point bending experiment, 100 distributions of aggregates and cement matrix were considered, and fracture factor and integral J were investigated, and contrary to expectations, the second and third fracture modes were also created. Besides, energy release ratio distribution along the beam thickness becomes unsymmetrical, contributing to early failure and crack propagation.
\end{abstract}

Keywords

fracture mechanics, meso-scale, stress intensity factor, integral J

\section{Introduction}

Failure mechanics process in quasi-brittle and brittle materials, such as concrete, is very complicated due to the propagation of cracks and involvement of cracks and grains [1-3]. Experiments and numerical analyses of concrete under different loadings indicate that concrete fracture behavior depends on its internal structure including the aggregate size, its distribution curve, mortar volume, and porosity. Therefore, the realistic description of the concrete fracture is obtained only when the factors mentioned are considered in concrete modeling. Since about 70 to 80 percent of the concrete volume is composed of sand and gravel, aggregate size and location in modeling have attracted the attention of researchers [4]. Crack usually initiates in ITZ zone and may pass through the cement matrix and even aggregates in case of continuation of crack growth. The width of this ITZ zone varies from 0 to $50 \mathrm{~mm}$ depending on aggregate roughness [5-7]. Meso-scale simulation of concrete can be performed using continuous [8-14] and discontinuous [15-18] models. It is also possible to use a discrete element method for concrete behavior modeling, which is a powerful numerical method for simulating the dynamic behavior of a set of separated particles [19-22]. This method is based on the use of an explicit numerical procedure that examines the interaction between particles by particle contact and motion in a particle-by-particle manner. Boundary Element Method using nonlinear finite elements [23] and also rigid body spring (mass-spring) method [24-26] are suitable for evaluating concrete failure behavior using concrete component modeling. A good understanding of concrete's failure behavior can be achieved using the spatial distribution of aggregates and concrete failure patterns. Thus, several experimental studies have been conducted including non-destructive testing methods in the acoustic techniques, and also X-ray scanning. The critical factor in failure modeling is 3D modeling [27, 28]. Calculating 3D semicircular disk modeling, Akhaveissy et al. [29] achieved more precise results for calculating the failure coefficient of a half-circle disk. Thus, in the present article, first, by comparing 2D and 3D modelling results, the 2D modelling error value was calculated. Given such considerable error, it is recommended to use $3 \mathrm{D}$ modelling for 
crack propagation analysis in heterogeneous cases such as concrete. Next step was to perform numerical modelling by LEFM method and non-linear method by considering the interaction between different components. After corroborating the modelling results by LEFM method, 100 different aggregate distributions were analyzed. Unlike expectations, due to the consideration of the aggregate in the cement matrix, the third mode of fracture was also created along with the first and second ones in the threepoint bending beam. Finally, given the uncertainty of the aggregate positioning, it is recommended to consider fracture parameters such as $\mathrm{K}$ and $\mathrm{J}$ in the same interval to be able to obtain more precise numerical predictions. It should be noted that, modelling via LEFM method is easyto-use and highly precise, and lacks the intricacies specific to non-linear models.

\section{Mechanical specification and geometry of the laboratory model}

In the present research, the specification of the experimental model proposed by Skarżyński et al. [13, 18] was used. Concrete beam has a length of $320 \mathrm{~mm}$, a height of $80 \mathrm{~mm}$ and a thickness of $40 \mathrm{~mm}$, and a notch has a width of 3 and a length of $8 \mathrm{~mm}$. The laboratory sample dimensions of the three-point concrete beam are shown in Fig. 1. The concrete sample homogeneous and heterogeneous mechanical properties and aggregates and cement matrix characteristics are shown in Table 1 and Table 2, respectively. In numerical modeling, the amount of air void in the concrete sample is discarded. The loaded charge is 2500 N. $\beta$ is the percentage of the total amount of aggregate in the concrete mix.

\section{Numerical modeling and verification method}

In order to calculate the crack tip stress intensity factor, the Linear Elastic Fracture Mechanics (LEFM) method was used. First, the concrete beam numerical model under homogeneous mechanical properties was analyzed, and the $2 \mathrm{D}$ and $3 \mathrm{D}$ modeling results were compared with the analytical equations of the LEFM, and the accuracy of the results was verified. Then, considering the four different grain sizes (Aggregate) and cement matrix in the limited space around the cracking Surface, the results were compared with LEFM. For 3D modeling of the concrete threepoint beam sample, a 3D 20-node element (Solid186) with three degrees of freedom per node was used. This element is potentially proper for the meshing of irregular geometries, and has the potential to be converted into
Table 1 Concrete sample specifications [13]

\begin{tabular}{lc}
\hline Concrete components & $\begin{array}{c}\text { Concrete mix } \\
\left(d_{50}=2 \mathrm{~mm}, d_{\max }=16 \mathrm{~mm}, \beta=75 \%\right) \\
\left(\mathrm{kg} \mathrm{m}^{-3}\right)\end{array}$ \\
\hline Cement & 810 \\
sand & 650 \\
Gravel aggregate $(2-8 \mathrm{~mm})$ & 580 \\
Gravel aggregate $(8-16)$ & 580 \\
Water & 340 \\
\hline
\end{tabular}

Table 2 Mechanical specifications of different concrete components [13]

\begin{tabular}{|c|c|c|c|c|c|}
\hline & \multicolumn{3}{|c|}{ Bulk elements } & \multicolumn{2}{|c|}{ Cohesive elements } \\
\hline & 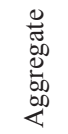 & 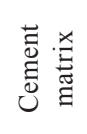 & 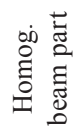 & 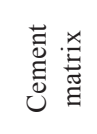 & $\stackrel{n}{N}$ \\
\hline$E[\mathrm{GPa}]$ & 47.2 & 29.2 & 36.1 & - & \\
\hline$v$ & 0.2 & 0.2 & 0.2 & - & \\
\hline$k_{n 0}[\mathrm{MPa} / \mathrm{mm}]$ & - & - & - & $10^{\wedge} 6$ & $10^{\wedge} 6$ \\
\hline$f_{t}[\mathrm{MPa}]$ & - & - & - & 4.4 & 1.6 \\
\hline$G_{F}[\mathrm{~N} / \mathrm{m}]$ & - & - & - & 40 & 20 \\
\hline$\alpha$ & - & - & - & 7.5 & 7.5 \\
\hline$\delta_{m}{ }_{m}^{f}[\mathrm{~mm}]$ & - & - & - & 0.071 & 0.098 \\
\hline
\end{tabular}

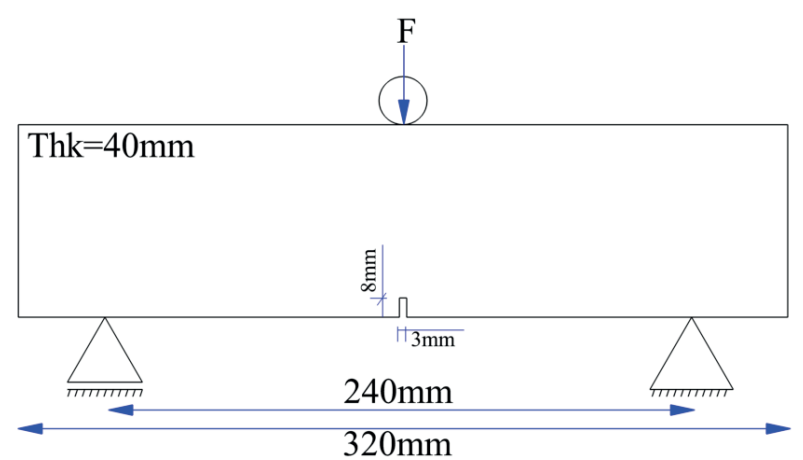

Fig. 1 Geometry of experimental concrete beams subjected to threepoint bending [13]

tetrahedral, pyramid and prism elements. For 2D modeling, the 2D 8-node element (Plane183) with two degrees of freedom per node was used. If required, this element also is naturally flexible to be converted into 6-node elements in irregular geometries. For the 2D model, due to the remarkable thickness of the concrete sample, the plane strain behavior was considered for the numerical model. In ANSYS software, high-order elements have the potential to resolve the Crack tip singularity. Twenty elements with a length of $0.5 \mathrm{~mm}$ were placed around the Crack tip. The meshing procedure of the model is shown in Fig. 2. 
In order to calculate the stress intensity factor, the amount in the finite element method, the crack surface displacement correlation method was used. In this method, given the extent of crack surface displacement, the stress intensity factor value is calculated. The displacement value of the crack surface in the LEFM is calculated via Eq. (1). According to the following Fig. 3 and Paris and Sih formulation [30], we have the following in polar space:

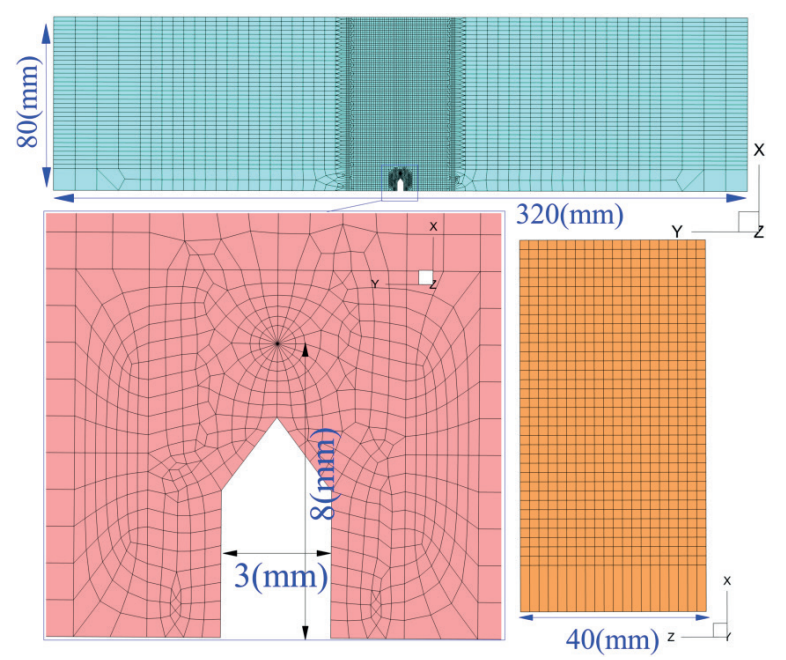

Fig. 2 Model dimensions and the finite element mesh

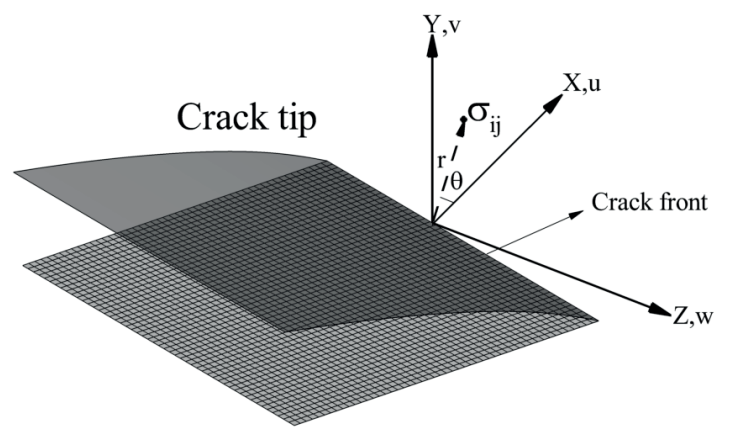

(a)

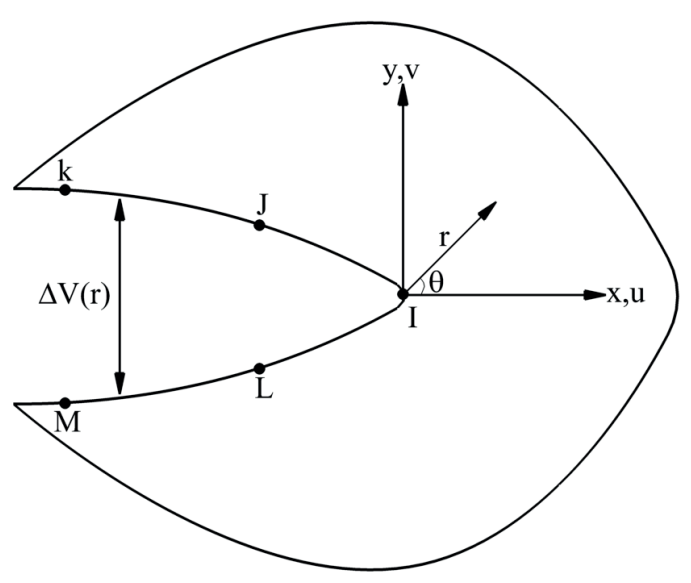

(b)

Fig. 3 a) Stress intensity factor calculation using displacement correlation; b) the opening of the crack plane in the 2Dimensional space
$u=\frac{K_{I}}{4 G} \sqrt{\frac{r}{2 \pi}}\left((2 \kappa-1) \cos \frac{\theta}{2}-\cos \frac{3 \theta}{2}\right)$

$-\frac{K_{I I}}{4 G} \sqrt{\frac{r}{2 \pi}}\left((2 \kappa+3) \sin \frac{\theta}{2}+\sin \frac{3 \theta}{2}\right)$,

$v=\frac{K_{I}}{4 G} \sqrt{\frac{r}{2 \pi}}\left((2 \kappa-1) \sin \frac{\theta}{2}-\sin \frac{3 \theta}{2}\right)$

$-\frac{K_{I I}}{4 G} \sqrt{\frac{r}{2 \pi}}\left((2 \kappa+3) \cos \frac{\theta}{2}+\cos \frac{3 \theta}{2}\right)$,

$w=\frac{2 K_{I I I}}{G} \sqrt{\frac{r}{2 \pi}}\left(\sin \frac{\theta}{2}\right)$.

$u, v, w$ is the displacement in the local Cartesian device according to Fig. 3, is the local polar coordinate in Fig. 3, $G$ is shear modulus, andare stress intensity factor

$\kappa=\left\{\begin{array}{ll}3-4 v & \text { if plane strain or axisymmetric } \\ \frac{3-v}{1+v} & \text { if plane stress }\end{array}\right.$.

Eq. (1) for $\theta= \pm 180^{\circ}$ (used for crack tip displacement) is summarized as follows:

$$
\left\{\begin{array}{l}
u=\frac{K_{I I}}{2 G} \sqrt{\frac{r}{2 \pi}}(1+\kappa) \\
v=\frac{K_{I}}{2 G} \sqrt{\frac{r}{2 \pi}}(1+\kappa) \\
w=\frac{2 K_{I I I}}{G} \sqrt{\frac{r}{2 \pi}}
\end{array}\right\} \stackrel{\text { full-crack model }}{\longrightarrow}\left\{\begin{array}{l}
K_{I}=\sqrt{2 \pi} \frac{G}{1+\kappa} \frac{|\Delta v|}{\sqrt{r}} \\
K_{I I}=\sqrt{2 \pi} \frac{G}{1+\kappa} \frac{|\Delta u|}{\sqrt{r}} \\
K_{I I I}=\sqrt{2 \pi} \frac{G}{4} \frac{|\Delta w|}{\sqrt{r}}
\end{array}\right\} .
$$

The Eq. (2) is true when $r \rightarrow 0$. Therefore, with respect to the numerical solution, using the path $k, J, I, L, M$, the limit should be determined. Thus, the Eq. (2) can be transformed as Eq. (3):

$$
\left.\begin{array}{l}
\frac{|v|}{\sqrt{r}}=A+B r \Rightarrow \lim _{r \rightarrow 0} \frac{|v|}{\sqrt{r}}=A \\
\stackrel{\text { half-crack model }}{\longrightarrow} K_{I}=\sqrt{2 \pi} \frac{4 G A}{1+\kappa}
\end{array}\right\} .
$$

Based on Eq. (3), the stress intensity factors per mode depend on two main factors: mechanical characteristics of material, and crack surface displacement. $G_{i}$ Depends on the mechanical properties of the element in question, and some of the elements around the crack tip are made of aggregates, and the rest are of the cement matrix according to the random distribution. To validate the finite element analysis results, the $K_{I}$ of the three-point beam (Fig. 1) was compared with the LEFM Eq. (4). For the three-point beam, the $K_{I}$ in the LEFM was calculated from Eq. (4). 
In Eq. (4), the function $f$ is the shape factor and depends on the geometric dimensions of the sample and the length of the crack. Also, "a" is crack length, $\mathrm{W}$ is the beam height, and $B$ is the thickness of the beam, $P$ is the force, and $S$ is the distance between the two supports.

$$
\left.\begin{array}{l}
K_{I}=\frac{P S}{B W^{1.5}} f(a / w) \\
f(a / w)=\frac{3\left(\frac{a}{w}\right)^{0.5}\left(1.99-\frac{a}{w}\left(1-\frac{a}{w}\right)\left(2.15-3.93\left(\frac{a}{w}\right)+2.7\left(\frac{a}{w}\right)^{2}\right)\right.}{2\left(1+2 \frac{a}{w}\right)\left(1-\frac{a}{w}\right)^{1.5}}
\end{array}\right\}
$$

By placing $S=240 \mathrm{~mm}, w=80 \mathrm{~mm}$, and $a=8 \mathrm{~mm}$, the three-point beam shape factor amounted to $f=0.846$. By $2 \mathrm{D}$ and $3 \mathrm{D}$ comparison of the numerical results with the analytical equations of LEFM, we can assure the finite element results (Table 3). However, according to the results, it is clear that even if homogeneous behavior is assumed, the 2D model results are different from the analytical equations and the 3D model, and this difference between the obtained results leads to decrease the accuracy of numerical models. This difference is due to the neglecting of the stress or strain vector across a particular direction, which causes tri-axial stress. According to Fig. 5, as there is no stress on the two sides of the sample, the plane stress conditions are dominant. By distancing from the external edges, the conditions in the 3D modelling tend to the plane strain. In contrast, in the 2D modeling, plane strain condition is constantly unchanged. 2D numerical model behavior is similar to the behavior of the plane in the middle of the thickness in the 3D modelling (Fig. 4). Thus, the 3D modelling behavior is a combination of plane stress behavior and plane strain. However, in 2D modelling, the issue is not taken into account. Accordingly, in examining the stress intensity factor in the fracture mechanics, it is better to use 3D modeling. In the next step, by 3D three-point beam modeling and taking into account the heterogeneous effects of the aggregates and cement paste, the concrete fracture parameters were investigated.

\section{3D modeling considering the distribution of aggregates in the Meso-scale}

Concrete consists of several materials with different mechanical behaviors that cause heterogeneous behavior, which changes the behavior of the concrete in the Meso and micro scale $[13,17,18]$, this change in the Meso and micro behavior scale compared to the macro scale contributes to the differences in numerical predictions. For example, in calculating the stress intensity factor in the concrete

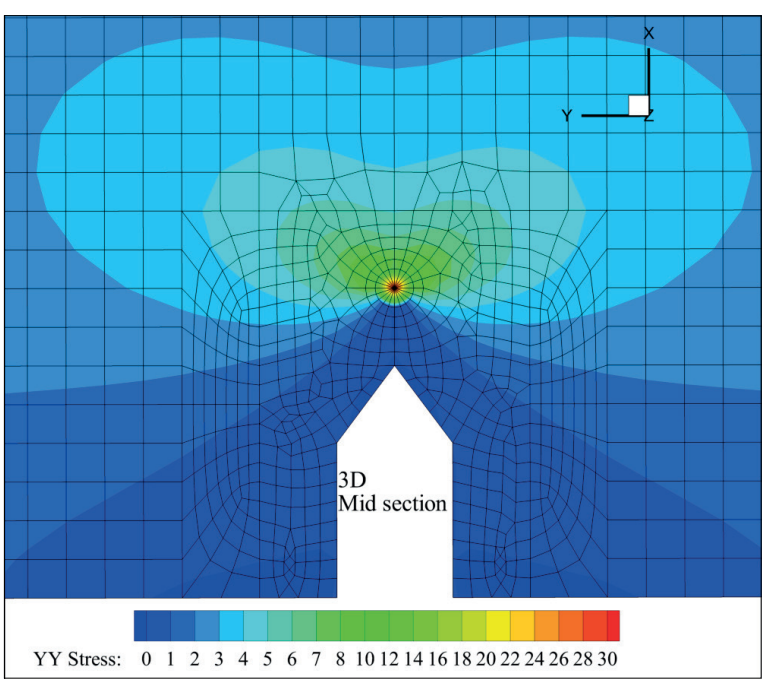

(a)

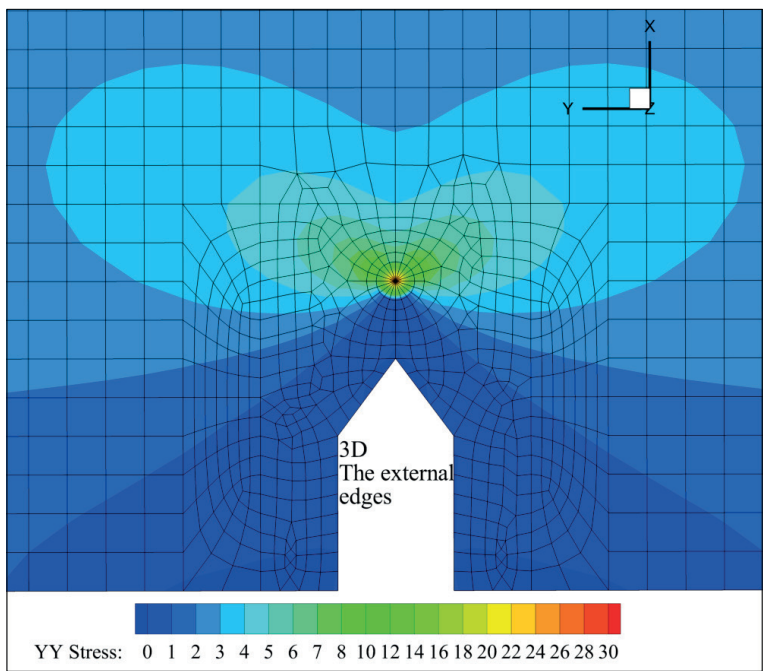

(b)

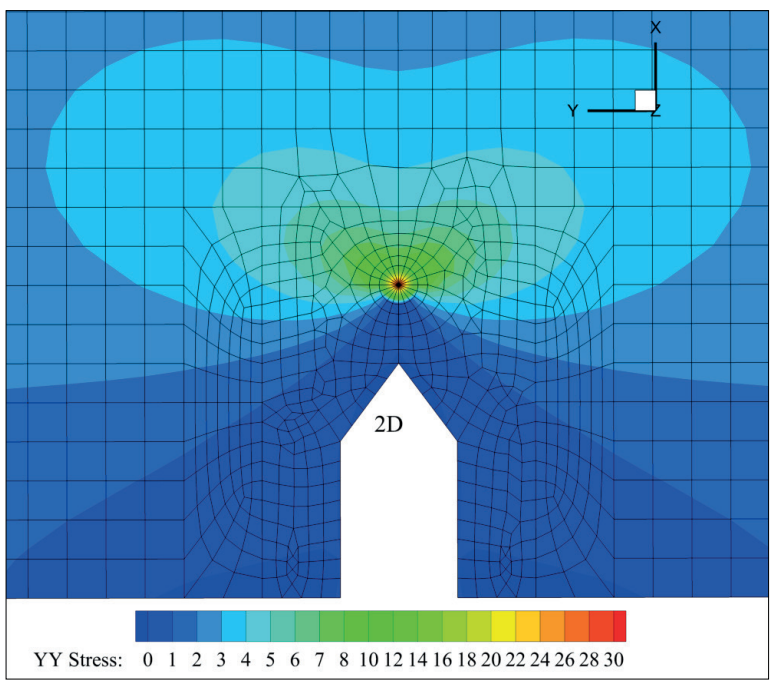

(c)

Fig. 4 A comparison of the stress contour along $y$ in the a) 3D and b) 2D modelling: outer aspect, middle plane along the thickness, c) 2D modelling 
Table 3 2D and 3D numerical result comparison and fracture mechanics analytical results

\begin{tabular}{ccc}
\hline & Method & $K_{I}(M P a \sqrt{m m})$ \\
\hline \multirow{2}{*}{$3 \mathrm{D}$} & FEM & 17.248 \\
& LEFM & 17.755 \\
$2 \mathrm{D}$ & FEM & 16.891 \\
\hline
\end{tabular}

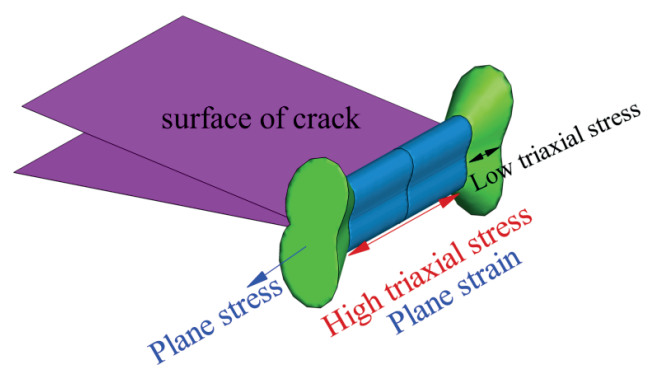

Fig. 5 Tri-axial stress conditions along the thickness

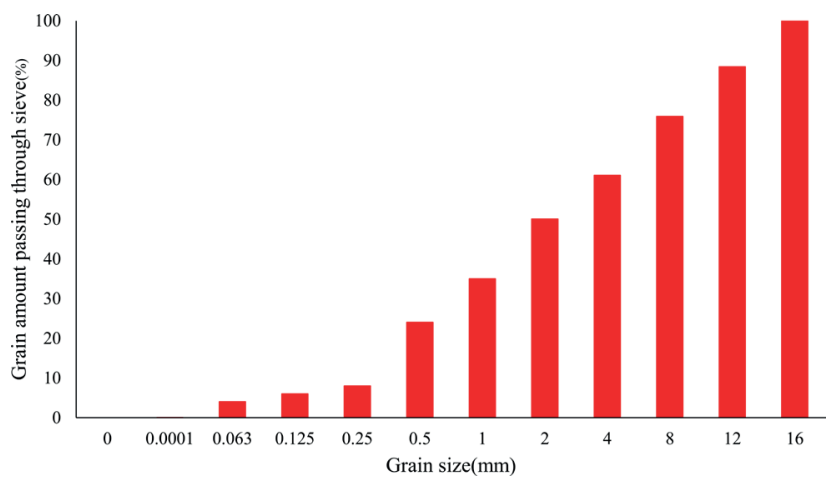

Fig. 6 Aggregate grading curve concrete

in terms of aggregates location and dimensions and material, and cement matrix, there are some differences in the results given the homogeneous behavior of concrete. In the following, according to the characteristics of the aggregates size of the experimental model [13], three types of aggregates with diameters of 12-16, 8-10, and 4-6 mm were considered for the numerical model construction. The aggregates dimensions were chosen due to having a greater effect on crack growth and stress intensity factor $[17,31,32]$. Therefore, these aggregates was modeled separately in the numerical model, and the remaining aggregate dimensions (sand) except the cement matrix was considered. Fig. 6 indicates the aggregates' granulation curve. Since the aggregate location in the concrete volume is not specified [33-35], Since a limited volume around the crack tip surface can be effective on the behavior and propagation of cracks and stress intensity factor, modeling of the whole sample in the Meso-scale is not necessary. Thus, only a volume of $25 \mathrm{~mm}$ from each side of the crack were considered for the modeling in the Meso-scale. Table 2 shows the mechanical behavior of each component.

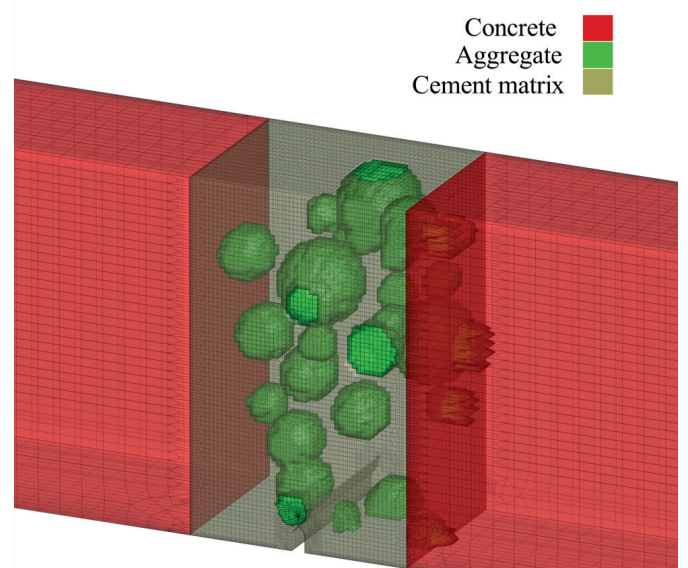

Fig. 7 One example of aggregate distribution and Meso-scale limited volume

The algorithm operates according to the aggregates equivalent radius and the number of aggregates. First, the first equivalent sphere is considered randomly in the cement matrix volume. Then, the nodes within the equivalent spheres are selected. If the nodes overlap, the sphere center changes again to the extent that there is no overlapping. The process continues until there are no two overlapping spheres. Then, the elements connected to the nodes are selected, and if the difference in the element size with aggregate is less than $1 \%$, the operation is acceptable. Otherwise, the elements connected to the nodes are unselected so that the volume difference becomes less than one percent.

Given that there is the possibility of aggregate distribution within the cement matrix, it is not possible to determine the location of the aggregate with certainty. Considering this issue in the present study, 100 different aggregate distributions were considered randomly to be able to take into account any changes in the analyses results as far as possible. In the numerical model threephase, there are homogeneous, cement matrix and aggregate, which the elements' dimensions in the Meso zone are $0.5 \mathrm{~mm}$, and the numerical model has a total of 1725028 degrees of freedom. Fig. 7 shows a randomized sample of the finite element model. The model shows one sample of the Meso-scale, aggregates, cement matrix and homogeneous concrete. Fig. 8 represents the six aggregate distribution samples in the cement matrix.

\section{Numerical modelling method and verification on Meso-scale}

In this part, to be ensured of the data results via LEFM method, a random sample is modeled by taking into account the interaction between different modelling components. To consider the interaction between different components, 
the 3D element (Interface 205) is used (Fig. 9). Two different interactions between aggregates and cement matrix (ITZ) and between cement matrix elements were considered. The mechanical properties of each component and their specific interaction are presented in Table 2.

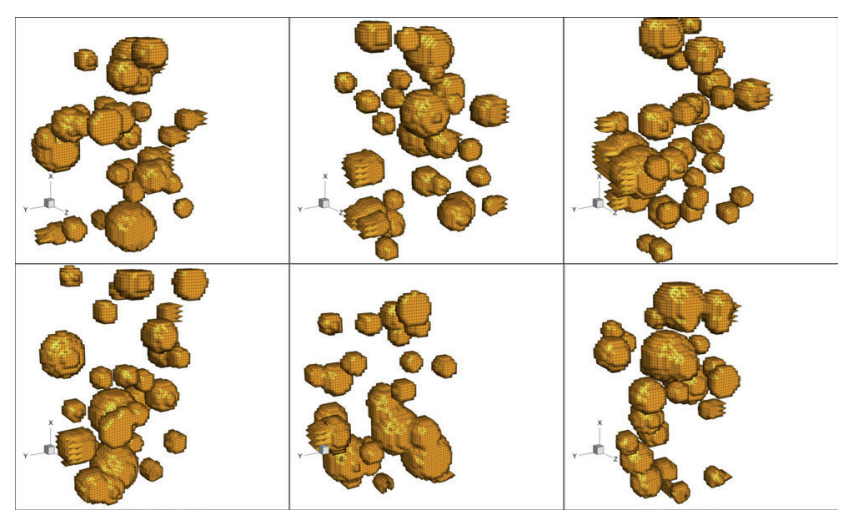

Fig. 8 Six examples of aggregates distribution
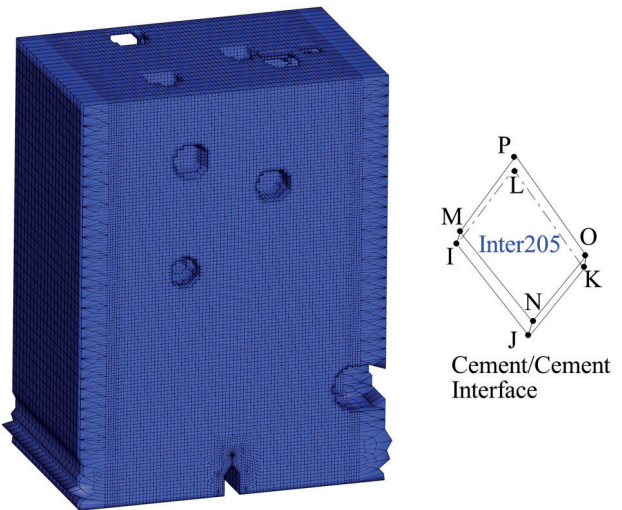

(a)

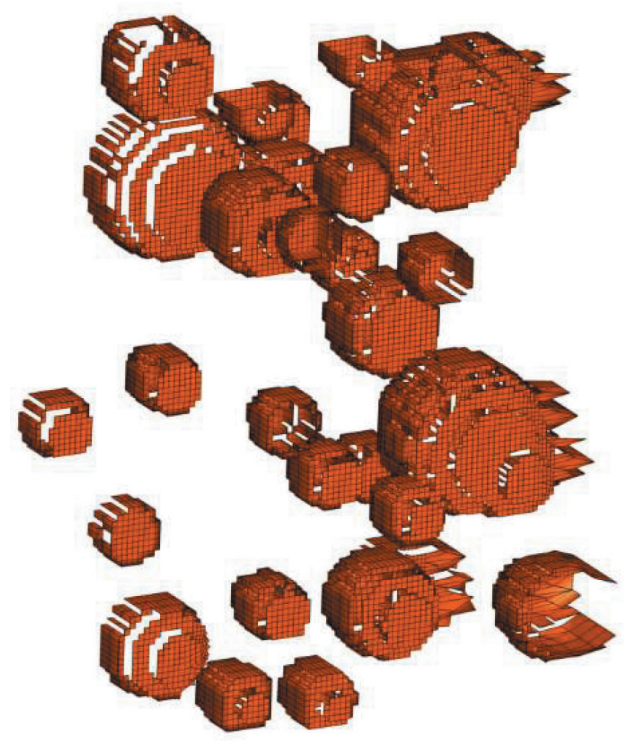

(b)

Fig. 9 a) Cement matrix and cement/cement interface; b) Aggregate/ cement interface (ITZ)

\subsection{Modelling via LEFM method without consideration of interaction between components}

The results indicated that the existence of aggregates in the direction of crack propagation can contribute to stress concentration. Such concentration can give rise to power path alteration, and accordingly, second and third modes of fracture come on the scene (Fig. 11). Fig. 10 clearly shows that the aggregates have hindered (blacked) or transformed strain generation path.

Unlike the expectations, this stress concentration can lead to second and third modes of fracture. By computing the stress intensity factor along the thickness, it was indicated that, not only $K_{I}$ was reduced in aggregate location but also $K_{I I}$ and $K_{I I I}$ were generated (Fig. 12). In the case $K$ $>K_{C}$, crack propagation is highly likely to occur [36-39]. Thus, if the sample was modelled via homogeneous behavior, the effect of the second and third modes would be overlooked, and there was a high risk in numerical predictions.

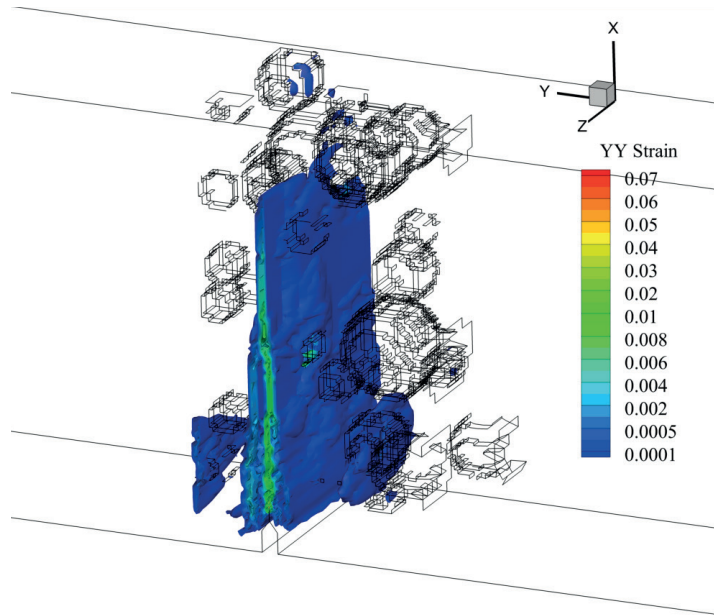

(a)

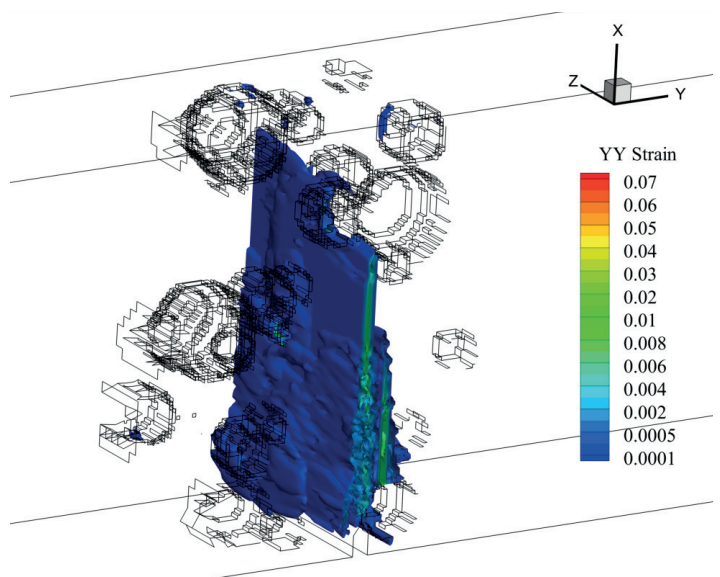

(b)

Fig. 10 YY strain a) Forward view; b) Back view 


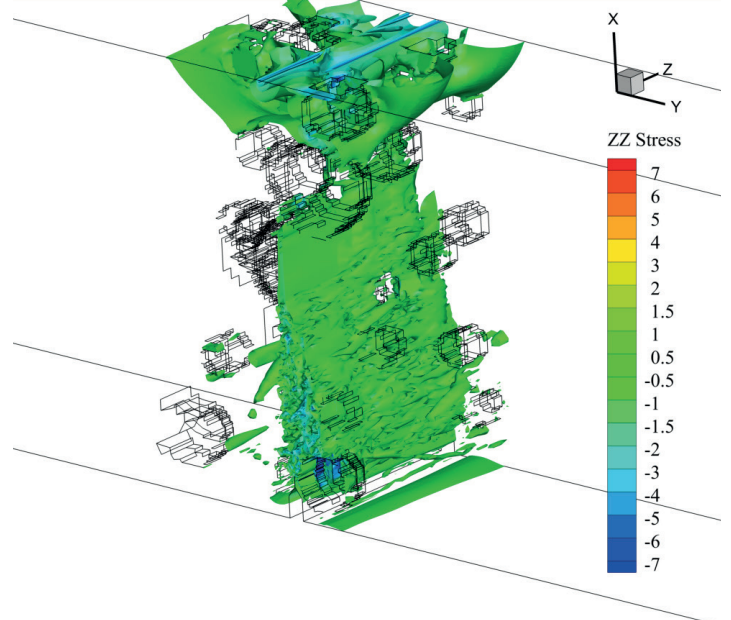

Fig. $11 \mathrm{ZZ}$ stress, the concentration of the stress generated around aggregate along the thickness

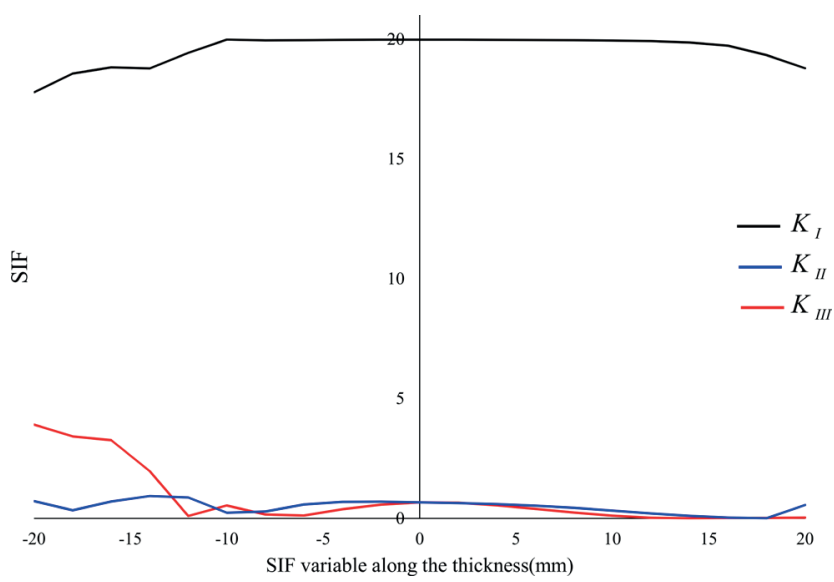

Fig. 12 Stress intensity factor along the numerical sample thickness

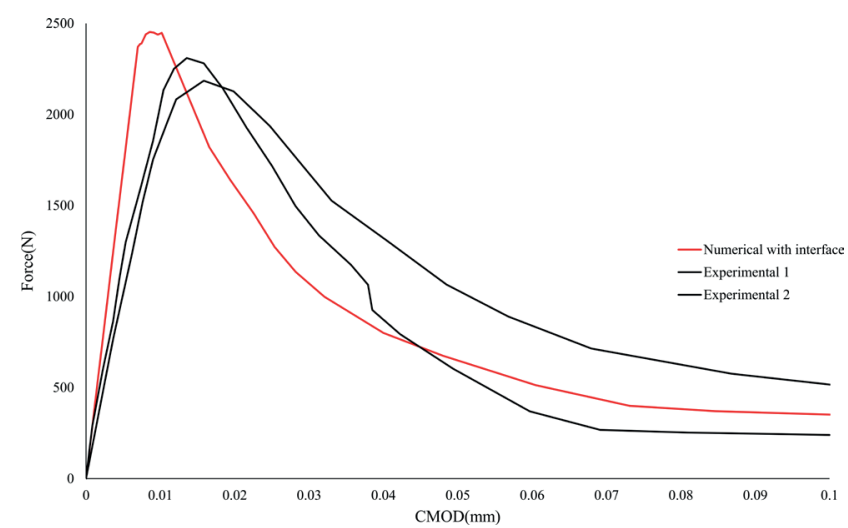

Fig. 13 Force-CMOD, Compression between numerical and experimental [13]

\subsection{Modelling by considering the interaction between components (interface element)}

In this model, the interaction between the aggregates and cement matrix (ITZ) and between the cement matrix elements was considered (Fig. 9). By considering the interaction, there is a high feasibility of separation between

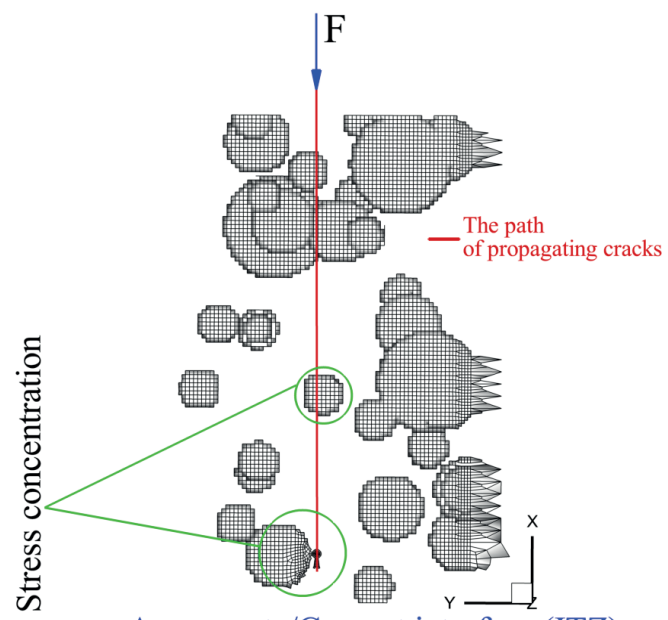

Aaggregate/Cement interface (ITZ)

(a)

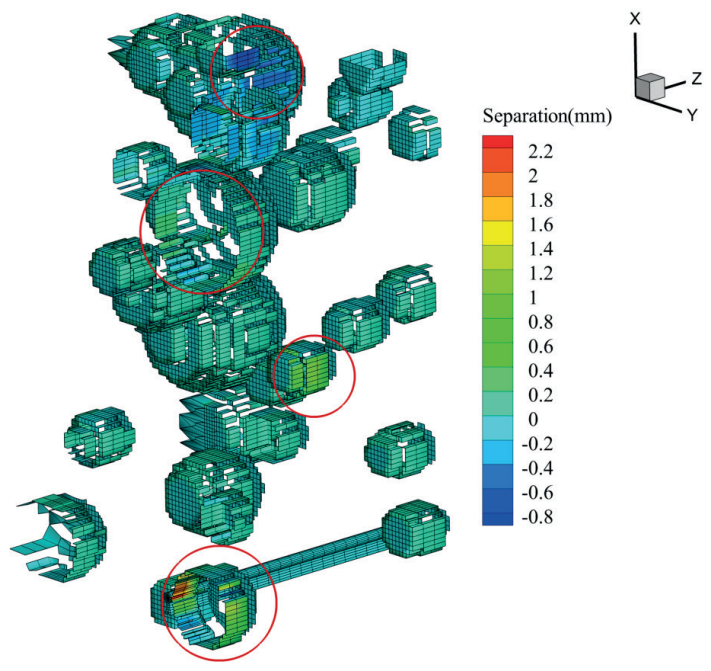

(b)

Fig. 14 a) Prediction of crack prediction; b) separation ITZ zone

different components. The results indicate that there is an acceptable consistency between the numerical and experimental results (Fig. 13). It is quite clear that although the model benefits from a high precision, it has a high computational expense, and it must be utilized in terms of the precision required.

Given that the three-point beam is under the first mode fracture, it is expected that the crack propagates via opening mechanism (first mode fracture) (Fig. 14(a)). However, given aggregate goniometrical form and positioning, such propagation may be susceptible to alteration. Interface elements between aggregates and cement matrix are presented in Fig. 9. The two aggregates specified in the Fig. 14(a) are located in the direction of the crack propagation. The aggregates have totally separated, and the crack has propagated in ITZ zone between two aggregates and 
cement matrix (Fig. 14). LEFM method results in Fig. 10 and Fig. 11 are totally consistent with the below results, and we can be completely assured of the corroboration of the modelling via LEFM method.

In the next step, in the numerical model in which the components behave interactively, the stress intensity factor per loading step was extracted. As expected, the stress intensity factor value is always smaller than LEFM value in a non-linear method, and at the end of loading and crack propagation, non-linear stress intensity factor value tends to LEFM stress intensity factor value [40]. The issue is studied by Wecharatan \& Shah [41], Sok et al. [42], Brown [43], and Entov and Yagust [44], and the present research results are in consistency with the same results. This issue can be a reason underlying the use of the stress intensity coefficient parameter for the concrete, because always $K_{L E F M} \geq K_{\text {Nonlinear }}$ (Fig. 15), and undoubtedly, when the stress intensity coefficient results in LEFM method reach the concrete toughness, crack propagation takes place. In the following, given the assurance of the corroboration of the LEFM method results, the effect of distribution of 100 random aggregate samples on the cement matrix is analyzed.

\section{Results}

In this part, the effect of the Meso-scale volume on the results is analyzed. Trawiński et al. [18] selected the limited $25 \mathrm{~mm}$ width from each side of the crack plane for Meso-scale modelling. To show the effect of the selected volume in Meso-scale modelling, one sample was selected. The beam was first totally modelled on Meso-scale. Then, given that the beam height is $80 \mathrm{~mm}$, the height was divided into four parts. In the first analysis, only A1 volume was selected for Meso-scale. In the next analyses, the volumes 2, 3, and 4 were also added to indicate the effect of modelling volume on Meso-scale (Fig. 16).

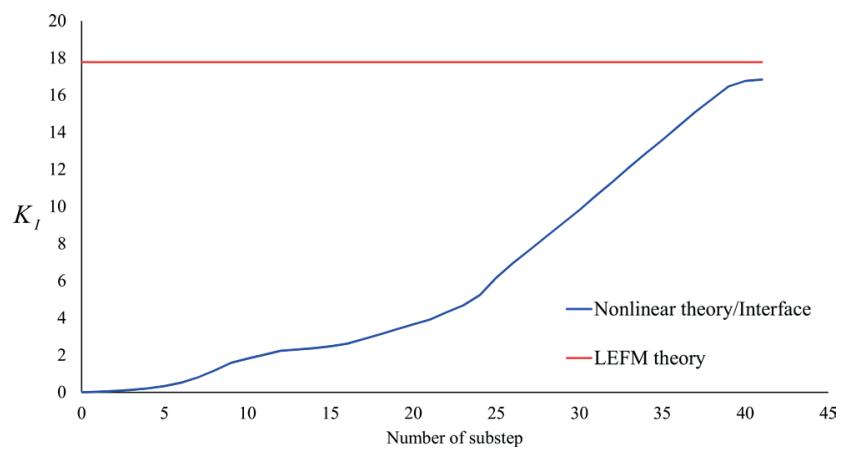

Fig. 15 Compression between KLEFM and KNonlinear

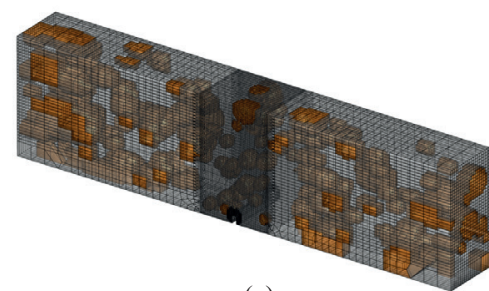

(a)

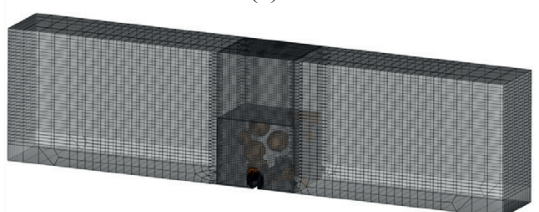

(d)

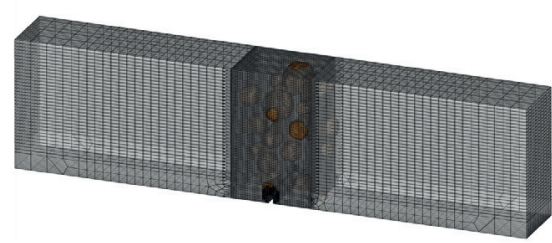

(b)

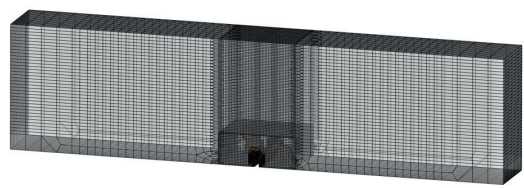

(e)

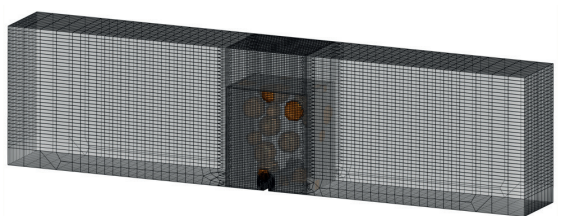

(c)

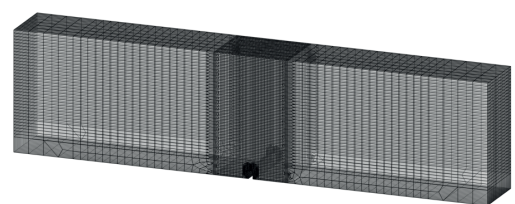

(f)

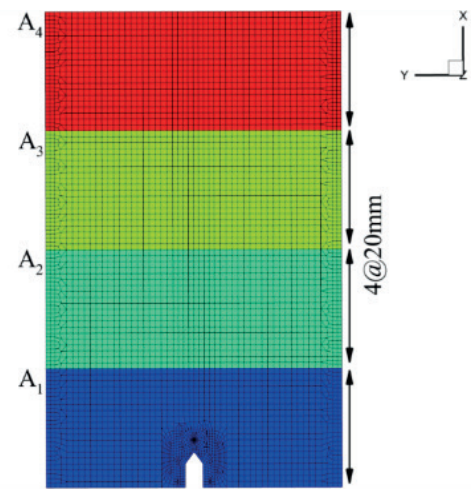

(g)

Fig. 16 Different Meso-scale volumes a) Total model; b) beam 0.75 height; c) beam 0.5 height; d) beam 0.25 height; e) homogeneous;

f) total beam height; g) Meso-scale selection procedure 


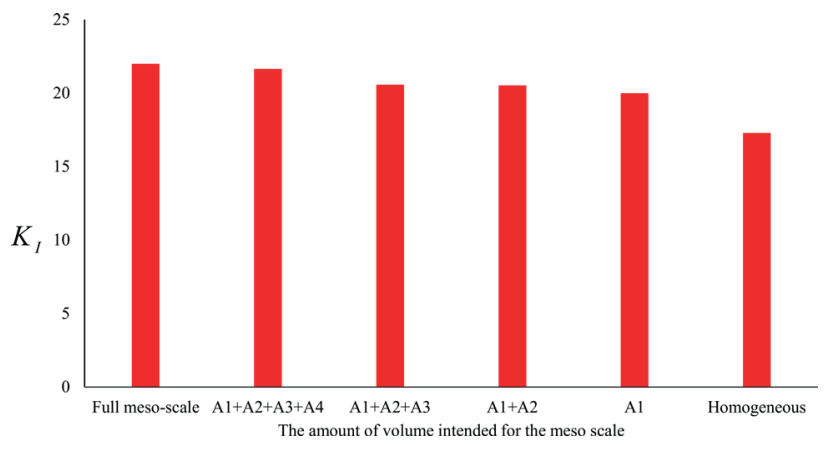

Fig. 17 Compression of K- the amount of volume intended for the Meso-scale

As indicated in Fig. 17, whatever the Meso-scale volume is greater, stress intensity factor is more precise. More important point in the Meso-scale volume selection is computational cost. By an increase in Meso-scale volume, computational cost and degrees of freedom increases dramatically. Given the following results, the same volume limited to $25 \mathrm{~mm}$ from each direction of crack plane was selected for the Meso-scale modelling.

In the following analyzing 100 samples and examining the results indicates that with the Meso-scale modeling and considering the interaction between the aggregates and cement matrix, the results have completely changed compared to the modeling under homogeneous behavior. This is because, in the homogeneous model, it is expected that the tip of the crack under the three-point beam experiment has only the $K_{r}$. However, the $K_{I I}$ and $K_{I I I}$ were also created driven by the presence of the aggregates. Taking into account homogeneous behavior for the sample in LEFM, the $K_{I}$ is $17.755 \mathrm{MPa} \sqrt{\mathrm{mm}}$. In contrast, taking into account the inhomogeneity effects, the $K_{I}$ varies from 12.2 to $22.5 \mathrm{MPa} \sqrt{\mathrm{mm}}$. According to Fig. 18, the $K_{I I}$ and $K_{I I I}$ are also significant, and the values may cause an early fracture of the sample. This issue is more important with regard to Fig. 19 because, considering the homogeneous behavior of concrete, the $K$ is equal to the $K_{I}(17.755 \mathrm{MPa} \sqrt{\mathrm{mm}})$. In contrast, taking into account the heterogeneous behavior of concrete, the $K$ is the sum of $K_{I}, K_{I I}$ and $K_{I I I}$. In most of 100 samples (except two samples) studied in the present research, the $K$ under heterogeneous behavior is greater than the $K$ under homogeneous behavior. Thus, as the stress intensity coefficient in the heterogeneous model is larger, the crack is highly likely to be propagated in the model. In contrast, the crack in the homogenous model remains under a safe state. Therefore, when the modeling is performed under heterogeneous behavior, crack propagation is likely to happen, and vice versa.

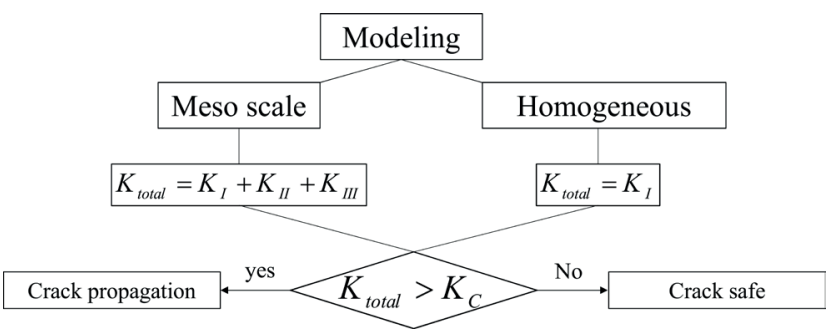

Fig. 18 Effect of modeling type on crack growth

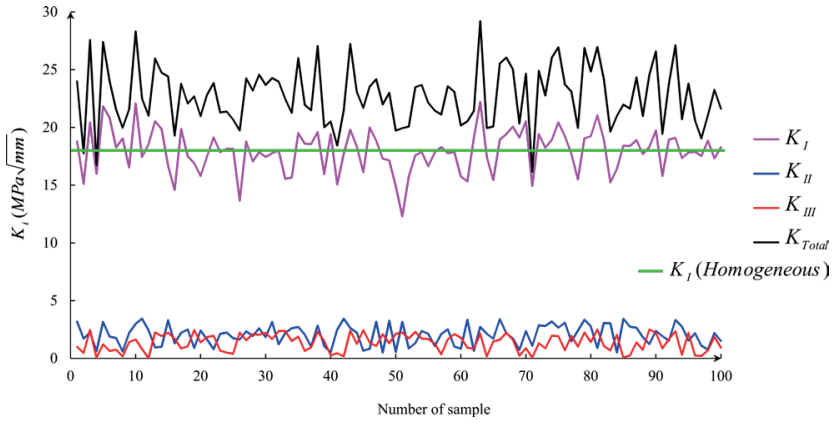

Fig. $19 K$ values for 100 samples

Examining the stress around the tip in Fig. 20 clearly shows that the stress contours pattern in the sample is uniform and symmetrical with homogeneous behavior according to the Irwin analytic model [45] and shows the correctness of the analysis, but taking into account the heterogeneous effects of the aggregates and cement matrix, the symmetry pattern is disintegrated around the tip, and the disintegration may contribute to early failure of the sample. In contrast, in modeling with homogenous behavior, the failure is not likely to occur.

For example, in one of the 100 numerical samples, an aggregate is randomly located at the tip of the crack in the exterior of the numerical model. According to the $K_{I}$ values, a stress concentration was created along the thickness and at the connecting point between the aggregates and cement matrix due to the different mechanical behaviors of the aggregate and cement matrix. Fig. 21 shows that the $K_{I}$ increased from 14.3 to $21.5 \mathrm{MPa} \sqrt{\mathrm{mm}}$ at the connecting point between the aggregate and cement matrix. This increase can significantly contribute to the further crack growth and crack direction alteration, which this case is not considered in the homogeneous behavior modeling. This can practically contribute to the growth and deviation of the cracks faster than the model with homogeneous behavior. Therefore, to analyze the crack in heterogeneous materials, it would be better to consider heterogeneity in numerical modeling to obtain more accurate predictions of the crack behavior. 


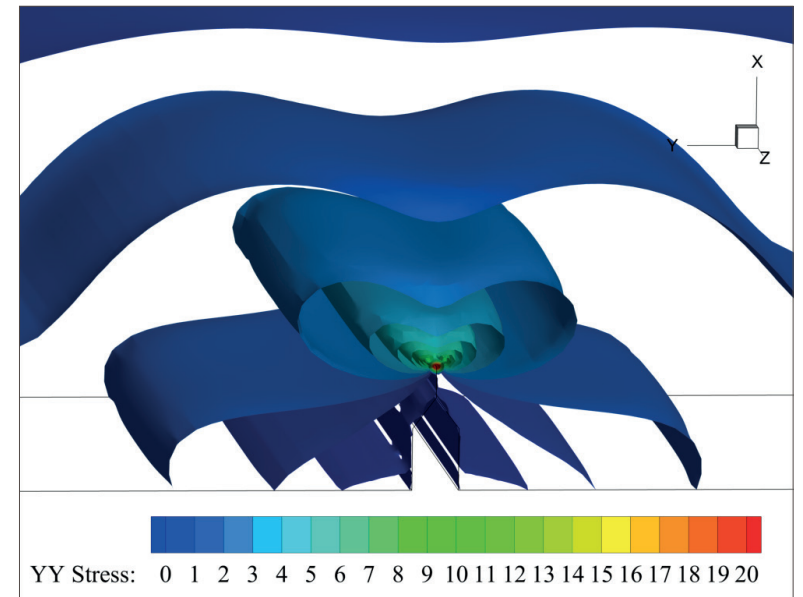

(a)

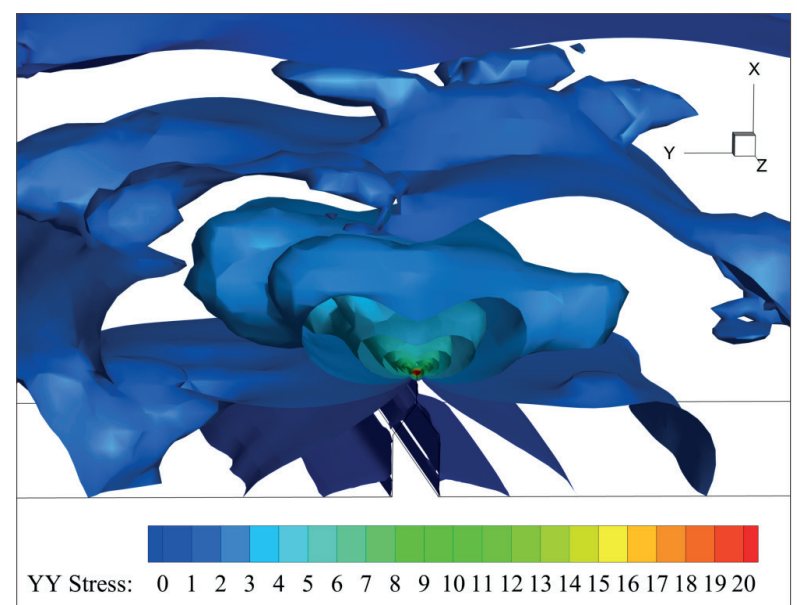

(b)

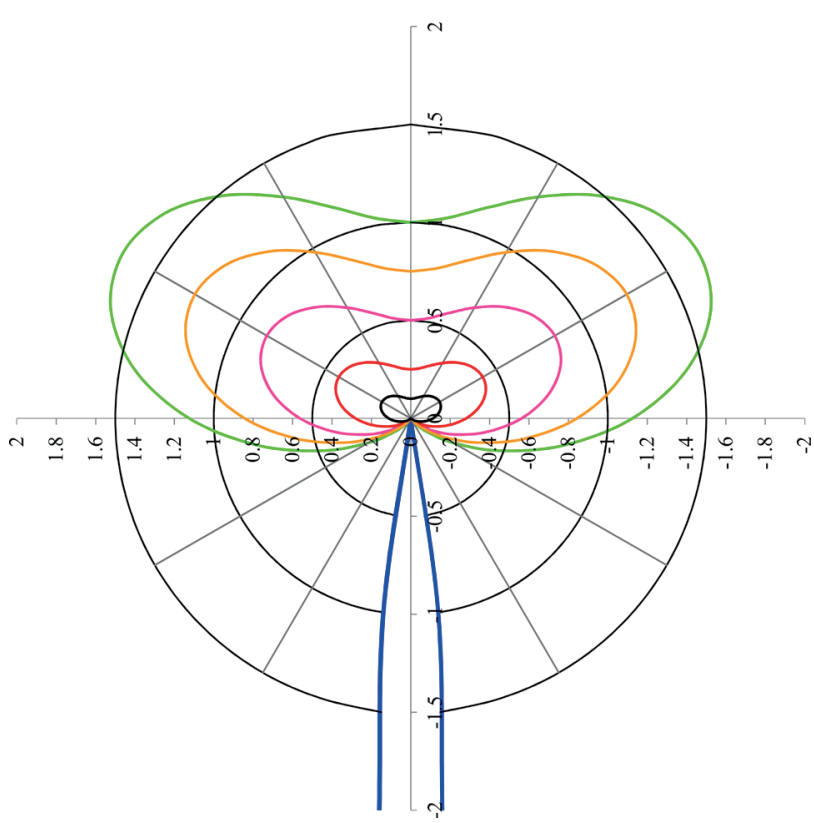

(c)

Fig. 20 Heterogeneity of stress due to aggregate modeling a) homogeneous; b) heterogeneous; c) Irwin analytic model

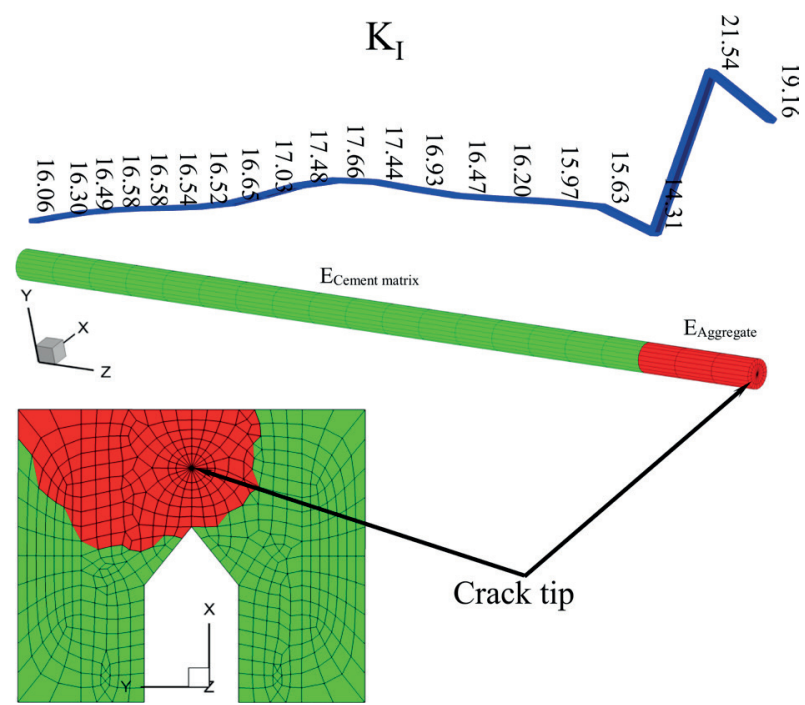

Fig. $21 \mathrm{KI}$ variable along the thickness

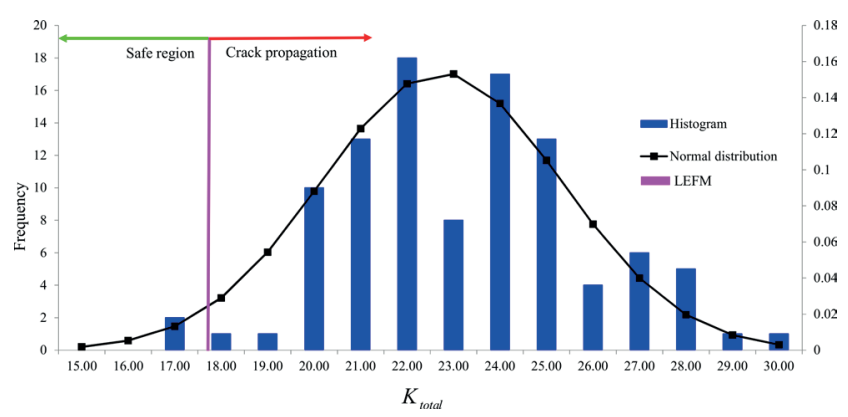

Fig. 22 The histogram of stress intensity factor

The Histogram (Fig. 22) represents the $K$ for 100 samples of the numerical model. The data follow a normal distribution, the mean of data is $22.74 \mathrm{MPa} \sqrt{\mathrm{mm}}$, which is significantly different from the $\mathrm{K}$ value in the homogeneous model. For example, if fracture toughness of a specific concrete sample is about $20 \mathrm{MPa} \sqrt{\mathrm{mm}}$, the $K$ related to the three modes of the three-point beam under the loading shown in Fig. 1 was $17.755 \mathrm{MPa} \sqrt{\mathrm{mm}}$ according to homogenous behavior, and the crack is stable. However, by the numerical analysis of the concrete sample at the Meso-scale, taking into account the heterogeneous effects of the aggregate distribution and cement matrix, conditions will be completely different, and $K$ value amounts to $22.74 \mathrm{MPa} \sqrt{\mathrm{mm}}$. As a result, the crack will grow, so it seems that the prediction based on the Meso model will be closer to reality.

\subsection{Investigate the $K$ changes along the thickness}

In this part, by comparing the integral $J$ value which represents the energy release rate in the LEFM and considers the effects of all three fracture modes, the differences between the model values with the homogenous behavior 
and Meso model can be observed (Fig. 23). For a better observation and comparison, in addition to the uncertainty region (response region of all 100 random samples), 10 samples results are also shown randomly. The variation in the amount of energy released rate in the thickness shows the exact difference between the model with the homogeneous behavior and model on Meso-scale. It can be said that the numerical model response with a non-homogeneous behavior has a higher value than that of the model with homogeneous behavior in the Meso-scale, and is a predictor of more accurate behavior. By comparing the relative error of the energy released rate in the model with the non-homogeneous behavior in the Meso-scale with the energy released rate in the model with homogeneous behavior in the thickness of the numerical model, it can be seen that there are sometimes over $50 \%$ difference between the two methods (Fig. 24). Given the accuracy of the model in Mesoscale, this difference causes the variation in the crack growth direction, which is not predicted in the analytical models with homogeneous behavior. Therefore, in examining crack propagation in non-homogeneous materials such as concrete, it is better to use 3D numerical modeling and to take into account the effect of aggregate or porosity in order to obtain an accurate analysis of the crack conditions.

\section{Conclusions}

Based on the 3D numerical modeling of the limited region surrounding the tip of the crack, in the numerical analyses, the concrete behavior can be predicted more accurately under heterogeneous behavior in the Meso-scale than under homogeneous behavior. In concrete behavior modeling in Meso-scale, it is of necessity to identify mechanical properties of components including sand and gravel and cement mortar. Depending on the extent of the numerical accuracy required by the experiment, different aggregate diameters should be considered and distributed using a loop algorithm in the Meso-scale under specific constraints. Given that the aggregate location in the cement matrix is not specified, 100 numerical models

\section{References}

[1] Bazant, Z. P., Planas, J. "Fracture and Size Effect in Concrete and Other Quasibrittle Materials", 1 st ed., CRC Press, Boca Raton, FL, USA, 1997. https://doi.org/10.1201/9780203756799

[2] Tejchman, J., Bobiński, J. "Continuous and Discontinuous Modelling of Fracture in Concrete using FEM", 1st ed., Springer, Berlin, Germany, 2012. https://doi.org/10.1007/978-3-642-28463-2 with different randomized aggregate distributions were considered in order to achieve a wide range of responses. Unexpectedly, following the sample analysis, both the firstmode stress intensity coefficient and the second and third mode stress intensity factor were obtained, contributing to an expansive change in the stress intensity coefficient. A comparison was made between the integral $J$ values in the total samples under heterogeneous behavior along the thickness with the integral $J$ value in one sample under homogenous behavior. The results indicate a wide range of the integral $J$ values and an over $50 \%$ difference can be observed between the integral $J$ values under the two behavior conditions. Taking into account the above difference, the modeling under homogeneous behavior seems to be less accurate. The wide range of the integral $J$ values corroborates the concrete failure toughness variability.

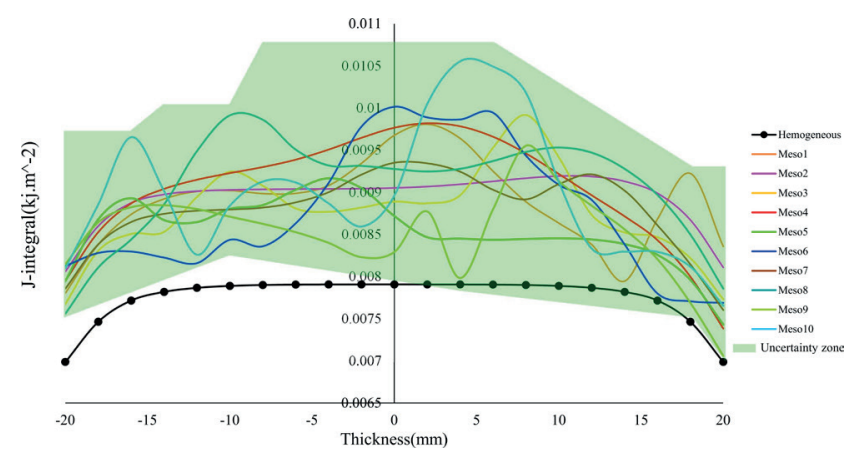

Fig. 23 Amount of energy released in the sample thickness

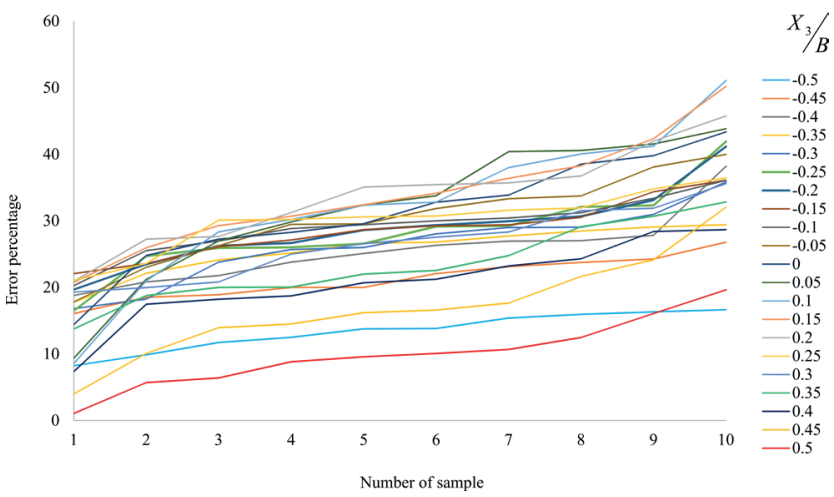

Fig. 24 Amount of relative error of energy released in homogeneous state and Meso-scale

[3] Lilliu, G., van Mier, J. G. M. "3D lattice type fracture model for concrete", Engineering Fracture Mechanics, 70(7-8), pp. 927-941, 2003. https://doi.org/10.1016/S0013-7944(02)00158-3

[4] Skarżyński, Ł., Nitka, M., Tejchman, J. "Modelling of concrete fracture at aggregate level using FEM and DEM based on X-ray $\mu \mathrm{CT}$ images of internal structure", Engineering Fracture Mechanics, 147, pp. 13-35, 2015. https://doi.org/10.1016/j.engfracmech.2015.08.010 
[5] Scrivener, K. L., Crumbie, A. K., Laugesen, P. "The Interfacial Transition Zone (ITZ) Between Cement Paste and Aggregate in Concrete", Interface Science, 12(4), pp. 411-421, 2004. https://doi.org/10.1023/B:INTS.0000042339.92990.4c

[6] Mondal, P., Shah, S. P., Marks, L. D. "Nanomechanical Properties of Interfacial Transition Zone in Concrete", In: Bittnar, Z., Bartos, P. J. M., Němeček, J., Šmilauer, V., Zeman, J. (eds.) Nanotechnology in Construction 3, Springer, Berlin, Germany, 2009, pp. 315-320. https://doi.org/10.1007/978-3-642-00980-8_42

[7] Königsberger, M., Pichler, B., Hellmich, C. "Micromechanics of ITZ-Aggregate Interaction in Concrete Part II: Strength Upscaling", Journal of the American Ceramic Society, 97(2), pp. 543-551, 2014. https://doi.org/10.1111/jace.12606

[8] Gitman, I. M., Askes, H., Sluys, L. J. "Coupled-volume multiscale modelling of quasi-brittle material", European Journal of Mechanics-A/Solids, 27(3), pp. 302-327, 2008.

https://doi.org/10.1016/j.euromechsol.2007.10.004

[9] Skarżyński, Ł., Tejchman, J. "Calculations of fracture process zones on meso-scale in notched concrete beams subjected to three-point bending", European Journal of Mechanics-A/Solids, 29(4), pp. 746$760,2010$.

https://doi.org/10.1016/j.euromechsol.2010.02.008

[10] Skarżyński, Ł., Tejchman, J. "Modelling the effect of material composition on the tensile properties of concrete", In: Weerhejm, J. (ed.) Understanding the Tensile Properties of Concrete, 1st ed., Woodhead Publishing, Cambridge, UK, 2013, pp. 52-97. https://doi.org/10.1533/9780857097538.1.52

[11] Kim, S.-M., Al-Rub, R. K. A. "Meso-scale computational modeling of the plastic-damage response of cementitious composites", Cement and Concrete Research, 41(3), pp. 339-358, 2011. https://doi.org/10.1016/j.cemconres.2010.12.002

[12] Shahbeyk, S., Hosseini, M., Yaghoobi, M. "Mesoscale finite element prediction of concrete failure", Computational Materials Science, 50(7), pp. 1973-1990, 2011.

https://doi.org/10.1016/j.commatsci.2011.01.044

[13] Skarżyński, Ł., Tejchman, J. "Experimental Investigations of Fracture Process in Concrete by Means of X-ray Micro-computed Tomography", Strain, 52(1), pp. 26-45, 2016. https://doi.org/10.1111/str.12168

[14] Li, Y., Schmitt, D. R. "Drilling-induced core fractures and in situ stress", Journal of Geophysical Research, Solid Earth, 103(B3), pp. 5225-5239, 1998.

https://doi.org/10.1029/97JB02333

[15] Ren, W., Yang, Z., Sharma, R., Zhang, C., Withers, P. J. "Twodimensional X-ray CT image based meso-scale fracture modelling of concrete", Engineering Fracture Mechanics, 133, pp. 24-39, 2015. https://doi.org/10.1016/j.engfracmech.2014.10.016

[16] Wang, X. F., Yang, Z. J., Yates, J. R., Jivkov, A. P., Zhang, C. "Monte Carlo simulations of mesoscale fracture modelling of concrete with random aggregates and pores", Construction and Building Materials, 75, pp. 35-45, 2015. https://doi.org/10.1016/j.conbuildmat.2014.09.069

[17] Wang, X., Zhang, M., Jivkov, A. P. "Computational technology for analysis of 3D meso-structure effects on damage and failure of concrete", International Journal of Solids and Structures, 80, pp. 310333, 2016.

https://doi.org/10.1016/j.ijsolstr.2015.11.018
[18] Trawiński, W., Bobiński, J., Tejchman, J. "Two-dimensional simulations of concrete fracture at aggregate level with cohesive elements based on X-ray $\mu \mathrm{CT}$ images", Engineering Fracture Mechanics, 168(A), pp. 204-226, 2016.

https://doi.org/10.1016/j.engfracmech.2016.09.012

[19] Sakaguchi, H., Mühlhaus, H.-B. "Mesh free modelling of failure and localization in brittle materials", In: Asaoka, A., Adachi, T., Oka, F. (eds.) Deformation and Progressive Failure in Geomechanics, Pergamon, Oxford, UK, 1997, pp. 15-21.

[20] D'Addetta, G. A., Kun, F., Ramm, E. "On the application of a discrete model to the fracture process of cohesive granular materials", Granular Matter, 4(2), pp. 77-90, 2002. https://doi.org/10.1007/s10035-002-0103-9

[21] Hentz, S., Donzé, F. V., Daudeville, L. "Discrete element modelling of concrete submitted to dynamic loading at high strain rates", Computers \& Structures, 82(29-30), pp. 2509-2524, 2004. https://doi.org/10.1016/j.compstruc.2004.05.016

[22] Nitka, M., Tejchman, J. "Modelling of concrete behaviour in uniaxial compression and tension with DEM", Granular Matter, 17(1), pp. 145-164, 2015.

https://doi.org/10.1007/s10035-015-0546-4

[23] Kozicki, J., Tejchman, J. "Effect of aggregate structure on fracture process in concrete using 2D lattice model", Archives of Mechanics, 59(4-5), pp. 365-384, 2007. [online] Available at: http://am.ippt. pan.pl/am/article/view/v59p365 [Accessed: 01 July 2019]

[24] Kikuchi, A., Kawai, T., Suzuki, N. "The rigid bodies - spring models and their applications to three-dimensional crack problems", Computers \& Structures, 44(1-2), pp. 469-480, 1992. https://doi.org/10.1016/0045-7949(92)90269-6

[25] Cusatis, G., Bažant, Z. P., Cedolin, L. "Confinement-shear lattice CSL model for fracture propagation in concrete", Computer Methods in Applied Mechanics and Engineering, 195(52), pp. 7154-7171, 2006. https://doi.org/10.1016/j.cma.2005.04.019

[26] Mariotti, C. "Lamb's problem with the lattice model Mka3D", Geophysical Journal International, 171(2), pp. 857-864, 2007. https://doi.org/10.1111/j.1365-246X.2007.03579.x

[27] Landis, E. N. "Micro-macro fracture relationships and acoustic emissions in concrete", Construction and Building Materials, 13(1-2), pp. 65-72, 1999. https://doi.org/10.1016/S0950-0618(99)00009-4

[28] Trawiński, W., Tejchman, J., Bobiński, J. "A three-dimensional meso-scale modelling of concrete fracture, based on cohesive elements and X-ray $\mu \mathrm{CT}$ images", Engineering Fracture Mechanics, 189 , pp. 27-50, 2018 https://doi.org/10.1016/j.engfracmech.2017.10.003

[29] Akhaveissy, A., Permanoon, A., Raeisi, R. "Analyzing the Edge Cracked Semicircular Disc under Uniform Compressive (ECSD(UD)) Load", Periodica Polytechnica Civil Engineering, 62(2), pp. 353-362, 2018. https://doi.org/10.3311/PPci.11111

[30] Paris, P. C., Sih, G. C. "Stress Analysis of Cracks" In: Fracture toughness testing and its applications", 1st ed., American Society for Testing and Materials (ASTM) and National Aeronautics and Space Administration (NASA), Baltimore, MD, USA, 1965, pp. 30-81. 
[31] Yılmaz, O., Molinari, J.-F. "A mesoscale fracture model for concrete", Cement and Concrete Research, 97, pp. 84-94, 2017.

https://doi.org/10.1016/j.cemconres.2017.03.014

[32] Huang, Y., Yang, Z., Ren, W., Liu. G., Zhang, C. "3D meso-scale fracture modelling and validation of concrete based on in-situ X-ray Computed Tomography images using damage plasticity model", International Journal of Solids and Structures, 67-68, pp. 340-352, 2015

https://doi.org/10.1016/j.ijsolstr.2015.05.002

[33] Zhang, Z., Song, X., Liu, Y., Wu, D., Song, C. "Three-dimensional mesoscale modelling of concrete composites by using random walking algorithm", Composites Science and Technology, 149, pp. 235245, 2017. https://doi.org/10.1016/j.compscitech.2017.06.015

[34] Huang, J., Peng, Q., Hu, X., Du, Y. "A combined-alpha-shape-implicit-surface approach to generate $3 \mathrm{D}$ random concrete mesostructures via digital image processing, spectral representation, and point cloud", Construction and Building Materials, 143, pp. 330-365, 2017. https://doi.org/10.1016/j.conbuildmat.2017.03.104

[35] Xu, W., Han, Z., Tao, L., Ding, Q., Ma, H. "Random non-convex particle model for the fraction of interfacial transition zones (ITZs) in fully-graded concrete", Powder Technology, 323, pp. 301-309, 2018. https://doi.org/10.1016/j.powtec.2017.10.009

[36] Náhlík, L., Štegnerová, K., Hutar̆, P. "Estimation of critical applied stress for crack initiation from a sharp V-notch", Theoretical and Applied Fracture Mechanics, 93, pp. 247-262, 2018. https://doi.org/10.1016/j.tafmec.2017.09.002

[37] Sih, G. C., DiTomasso, A. (eds.) "Fracture mechanics of concrete: Structural application and numerical calculation", 1st ed., Martinus Nijhoff Publishers, Dordrecht, Netherlands, 1985.

https://doi.org/10.1007/978-94-009-6152-4
[38] Tutluoglu, L., Keles, C. "Mode I fracture toughness determination with straight notched disk bending method", International Journal of Rock Mechanics and Mining Sciences, 48(8), pp. 1248-1261, 2011. https://doi.org/10.1016/j.ijrmms.2011.09.019

[39] Ohtsu, M. "Crack propagation in concrete: Linear elastic fracture mechanics and boundary element method", Theoretical and Applied Fracture Mechanics, 9(1), pp. 55-60, 1988. https://doi.org/10.1016/0167-8442(88)90048-1

[40] Chauhan, D. R., Tewani, H. R., Kalyana Rama, J. S. "Application of Principles of Linear Elastic Fracture Mechanics for Concrete Structures: A Numerical Study", Applied Mechanics and Materials, 877, pp. 282-288, 2018.

https://doi.org/10.4028/www.scientific.net/AMM.877.282

[41] Wecharatana, M., Shah, S. P. "Resistance to crack growth in Portland cement composites", In: Chen, W. F., Ting, E. C (eds.) Fracture in Concrete, ASCE, New York, NY, USA, 1980, pp. 82-105.

[42] Sok, C., Baron, J., Francois, D. "Mecanique de la rupture appliquee au beton hydraulique", Cement and Concrete Research, 9(5), pp. 641-648, 1979. https://doi.org/10.1016/0008-8846(79)90149-2

[43] Brown, J. H. "Measuring the fracture toughness of cement paste and mortar", Magazine of Concrete Research, 24(81), pp. 185-196, 1972. https://doi.org/10.1680/macr.1972.24.81.185

[44] Entov, V. M., Yagust, V. I. "Experimental investigation of laws governing quasi-static development of macrocracks in concrete", Mechanics of Solids, 10(4), pp. 87-95, 1975.

[45] Irwin, G. R. "Analysis of stresses and strains near the end of a crack traversing a plate", Journal of Applied Mechanics, 24, pp. 361-364, 1957. 